\title{
Reconstruction and 3D visualisation based on objective real 3D based documentation
}

\author{
Michael J. Bolliger • Ursula Buck • Michael J. Thali • \\ Stephan A. Bolliger
}

Accepted: 15 September 2011/Published online: 7 October 2011

(C) Springer Science+Business Media, LLC 2011

\begin{abstract}
Reconstructions based directly upon forensic evidence alone are called primary information. Historically this consists of documentation of findings by verbal protocols, photographs and other visual means. Currently modern imaging techniques such as 3D surface scanning and radiological methods (Computer Tomography, Magnetic Resonance Imaging) are also applied. Secondary interpretation is based on facts and the examiner's experience. Usually such reconstructive expertises are given in written form, and are often enhanced by sketches. However, narrative interpretations can, especially in complex courses of action, be difficult to present and can be misunderstood. In this report we demonstrate the use of graphic reconstruction of secondary interpretation with supporting pictorial evidence, applying digital visualisation (using 'Poser') or scientific animation (using '3D Studio Max', 'Maya') and present methods of clearly distinguishing between factual documentation and examiners' interpretation based on three cases. The first case involved a pedestrian who was initially struck by a car on a motorway and was then run over by a second car. The second case involved a suicidal gunshot to the head with a rifle, in which the trigger was pushed with a rod. The third case dealt with a collision between two motorcycles. Pictorial reconstruction of the secondary interpretation of these cases has several advantages. The images enable an immediate overview, give rise to enhanced clarity, and compel the examiner to look at all details if he or she is to create a complete image.
\end{abstract}

M. J. Bolliger · U. Buck · S. A. Bolliger $(\square)$

Institute of Forensic Medicine, University of Bern, 3012 Bern,

Switzerland

e-mail: stephan.bolliger@irm.unibe.ch

M. J. Thali

Institute of Forensic Medicine, University of Zuerich,

8057 Zürich, Switzerland
Keywords Virtopsy · Forensic reconstruction · Digital visualisation · Primary information and secondary interpretation $\cdot$ 3D Studio Max $\cdot$ Maya

\section{Introduction}

Besides the gathering of forensic evidence, also referred to as "finding/factual documentation" or primary information, forensic examiners are also expected to present interpretations for the judicature, based on their experience. This is called secondary interpretation.

Secondary interpretation is directly based on primary information, such as documentation of victims, perpetrators, weapons, accident vehicles and crime/accident scenes, which may include autopsy protocols, photographs, sketches, chemical, toxicological and DNA analyses.

The quality of the interpretation, or even of a future reinterpretation, is obviously dependent on the quality of the factual documentation. Ideally, recorded factual documentation should make a detailed future re-analysis, or even obtaining a "second opinion" by uninvolved experts of a case, possible.

The aim of creating a detailed, factual documentation, making a future reanalysis possible, was one of the reasons for the founding of the Virtopsy ${ }^{\circledR}$ Project in Bern, Switzerland in the mid-nineties. The scanning of bodies, 3D optical surface scanning with multislice computed tomography (MSCT), magnetic resonance imaging (MRI) of victims and weapons/vehicles, gives rise to an accuracy and threedimensionality that conventional documentations lack, and allows for the re-examination of the corpse on recorded evidence, even decades later, after burial of the body [1-4].

The radiological post-mortem documentation approach has been implemented by many groups in post-mortem 
forensic investigations, for example the Office of the Armed Forces Medical Examiner (Armed Forces Institute of Pathology, Washington DC, Dover, Del), and groups from the universities of Copenhagen (Denmark) and Linkoping (Sweden), Melbourne (Australia) and Japan, who founded the Society for Autopsy Imaging in 2003 [5-8].

This enables accurate factual documentation (primary information) [9-11] and sufficient secondary interpretation, should the need arise. Secondary interpretation is based on primary information including real 3D documentations and reconstructions, and on the expert's experience.

Reconstructions can be given in the form of a written expertise or as an expert testimony at court, or play-acted at the incident scene and photographed and/or filmed using either accounts of the defendants or the victims (should they have recovered), or witnesses.

In this paper we demonstrate the possible use of forensic imaging in delivering a clear and easily understandable secondary interpretation as a pictorial interpretation of forensic cases.

\section{Materials and methods}

We selected three cases from ones assessed at our institute which demonstrate the distinction between primary information and secondary interpretation, with some of their pictorial documentation.

Primary information was collected by experienced board-certified forensic pathologists by matching the height from the ground, and the shape and the type of the detected lesions, to potentially injury-causing structures or objects.

Secondary interpretation was performed by two forensic pathologists (SB and MT) and an experienced accident investigator (UB) based on the primary information and their experience in comparable cases. These interpretations were then combined and elaborated by a visualisation specialist (MB) using Autodesk ${ }^{\circledR}$ 3Ds Max ${ }^{\circledR}$, and Autodesk ${ }^{\circledR}$ Maya ${ }^{\circledR}$.

These software programs provide tools for powerful, integrated 3D modelling, animation, rendering, and "compositing". They offer differentiated experiences and specialized toolsets for visualisation specialists as well as game developers, visual effects artists, graphic designers, architects, designers, and engineers.

\section{Results}

Case 1

A 63-year-old man involved in an accident on a motorway when overtaking another car got out of his car and tried to cross the motorway, upon which he was struck by one car and then run over by another car.

Apart from extensive blunt trauma to the head, trunk and extremities consistent with being run over, autopsy showed a tearing of the right cranial part of the chest with complete evisceration of the heart and partial evisceration of the lungs, a rectangular abrasion at the left hip with crushing of the underlying fatty tissue, fractures of the fibula and tibia on the left, a crushing of the subcutaneous fatty tissue on the left lower leg ventrally and the right knee medially, and a wedgefracture of the right humerus with a medially located base.

Investigations showed that the car that ran over the man had blood droplets on the roof. Both cars involved in the fatal accident had been travelling at approximately $120 \mathrm{~km} / \mathrm{h}$.

The district attorney requested clarification as to which car had killed the man.

\section{Detailed results and conclusion of case 1}

The first car displayed distinct damage. The right side of the bonnet was indented and showed black abrasions corresponding to the black trousers of the victim, and the right edge of the front bumper and the right side mirror were torn off and the front window was shattered near the right base (Fig. 1).

The crushing of the subcutaneous fatty tissue on the medial side of the right lower leg of the body corresponded to being hit by the right edge of the front bumper (Fig. 2). The torn off right side mirror correlated in shape and height to the abrasion on the victim's left trunk side. This primary information shows that the man was struck by the right side of the car (Fig. 3). As wedge fractures of long bones occur when a limb is struck at high speed and are, as a general rule, not encountered when run over, the right arm must have struck the windshield. No signs of a contact of the head with the first car could be found nor was the right arm lacerated. Therefore, neither the head nor the arm injury could account for the blood droplets found on the roof of the second car. We believe that, due to the very tangential, high-velocity impact, the victim was twirled along his body axis (Fig. 4), leading to a tearing of the chest and evisceration of the heart and lungs, and a resultant showering of blood droplets. This secondary interpretation, or more interpretative reconstruction, would explain the droplets of blood on the roof of the second car. We therefore concluded that the man was dead or dying when he was run over by the second car.

\section{Summary of case 1}

Primary information:

- Injuries to the body as described in the text.

- Damages to vehicles and bloodstains as described in the detailed results. 
Fig. 1 Overview of the major findings of the first car in case 1 . The numbers on the top right refer to the height above ground in centimetres
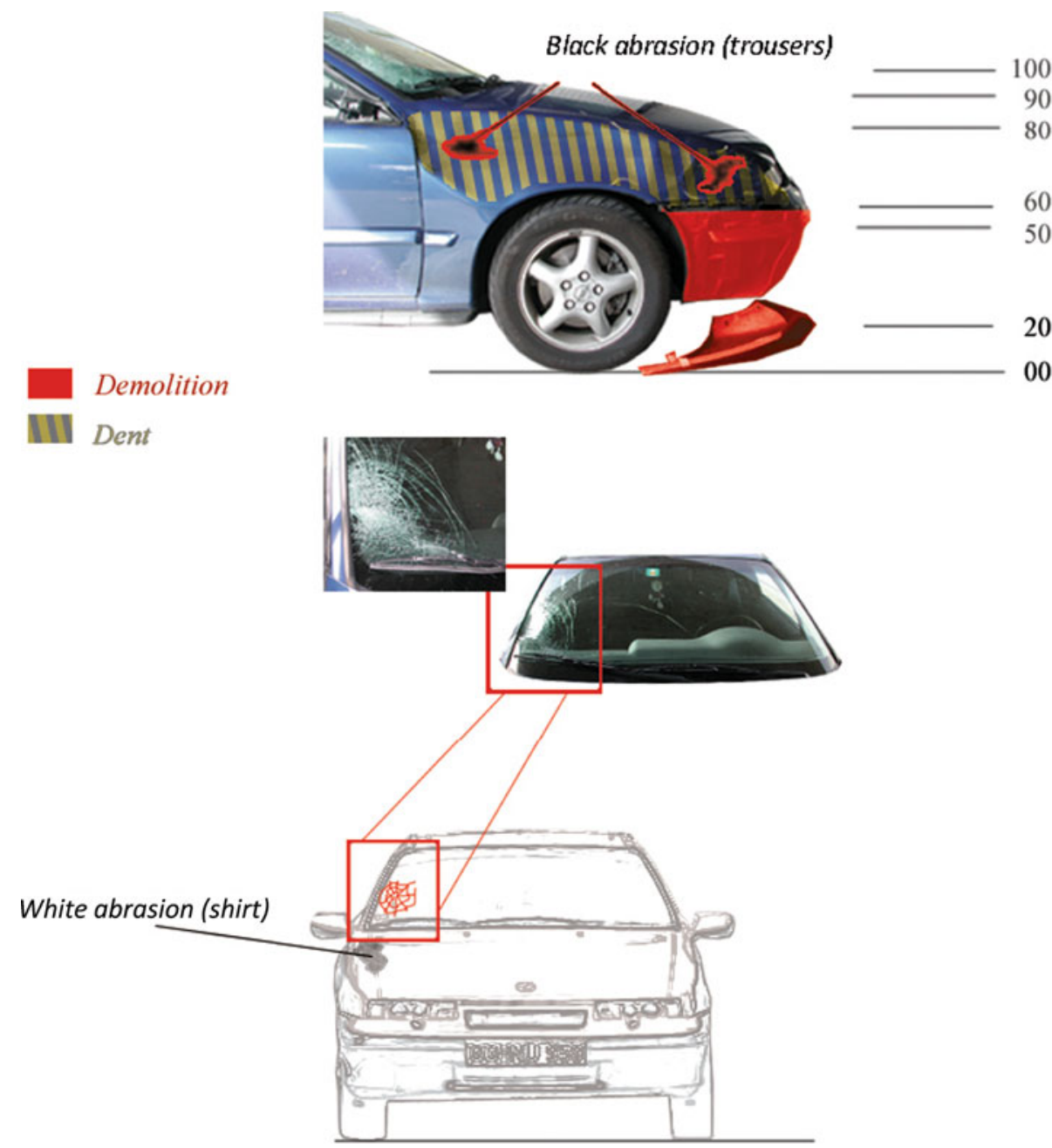

Secondary interpretation: (Tangential high velocity impact led to twirling of the victim and evisceration of the heart and lungs resulting in the showering of blood on the second car.

- Therefore, the man was dead or dying when he was run over by the second car.

\section{Case 2}

A man (body length $179 \mathrm{~cm}$ ) was found dead in his apartment. A rifle (total length $1.107 \mathrm{~m}$, calibre $7.5 \mathrm{~mm}$ ) lay roughly one metre away and a $62.5 \mathrm{~cm}$ long wooden rod with an-L-shaped steel hook was found in the immediate vicinity (Fig. 5).

The body showed a massive, $11 \times 12 \mathrm{~cm}$ large destruction of the right side of the face and a round defect of $2.3 \mathrm{~cm}$ diameter on the left side with surrounding abrasion (Fig. 6). The facial skeleton was severely damaged. The left shoulder showed an $11 \times 4 \mathrm{~cm}$ large defect on the ventral side and a $12 \times 8 \mathrm{~cm}$ large defect on the dorsal side (Fig. 7). The soft tissues and osseous structures of the shoulder were destroyed.

The presence of two through and through gunshot wounds, namely a contact gunshot to the right side of the head with bullet passage to the left and a through and through gunshot to the left shoulder (from ventral to dorsal) indicated the possibly of two separate gunshots. However, only one spent cartridge was present in the rifle and no other cartridges were found in the flat. Police investigators initially suspected a homicide. The purpose of the rod was not immediately clear. The body underwent MSCT scanning and a model of the corpse, the rifle, and the wooden rod, were created.

\section{Results of case 2}

Positioning the rifle to the entrance wound at the right side of the head made it obvious that the man could not have pulled the trigger in this position. However, if he had pushed the trigger with the hook on the rod, he could very easily have shot himself (Fig. 8). 
Fig. 2 Initial collision phase of the first car in case 1 with the pedestrian. The car and the pedestrian are drawn to scale. The blue colour indicates crushing of the subcutaneous fatty tissue

Fig. 3 Tangential contact of the car with the pedestrian. The humerus fracture (location coloured red) occurred due to contact with the windscreen pillar. The arm also broke the windscreen. The side mirror gave rise to the abrasion on the left side of the hip
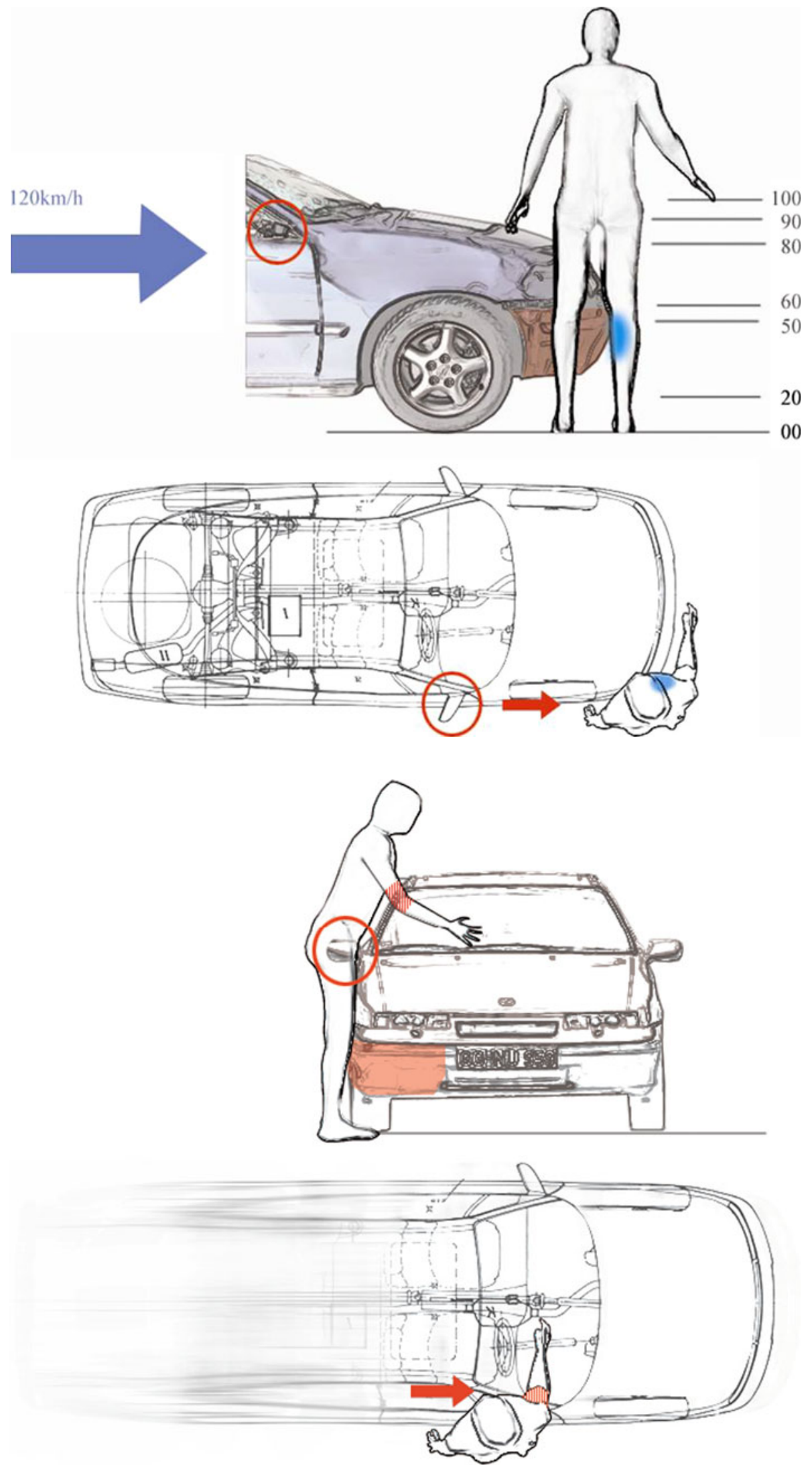
Fig. 4 Second-degree interpretation (coloured green); the pedestrian is twirled along his axis due to the contact with the side of the car, especially the side mirror. By twirling, the chest is torn open and blood is spattered in all directions. Some of the blood rained down on the following car (not shown)

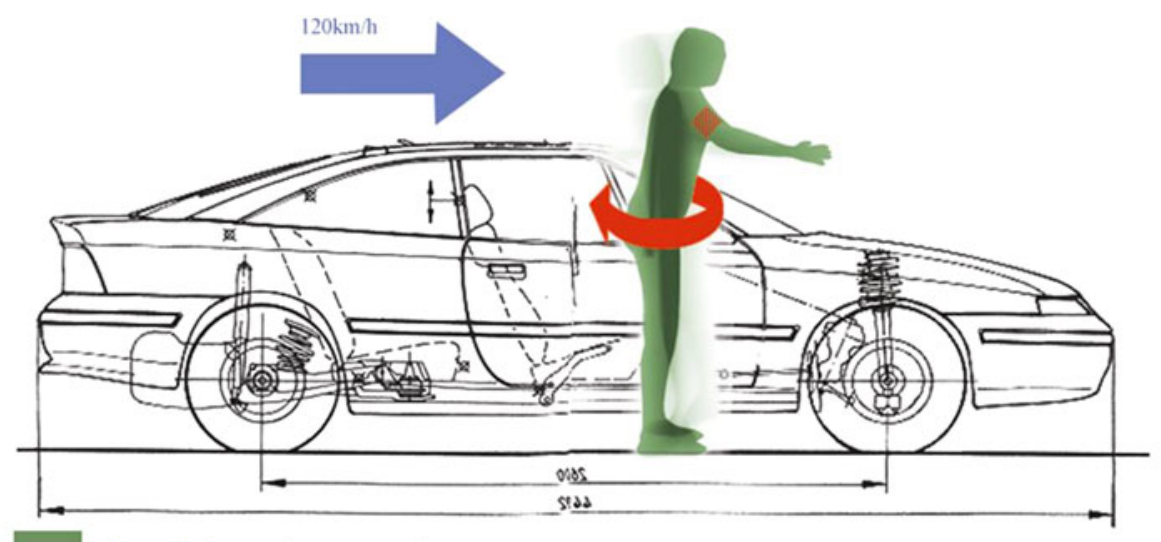

Second-degree interpretation

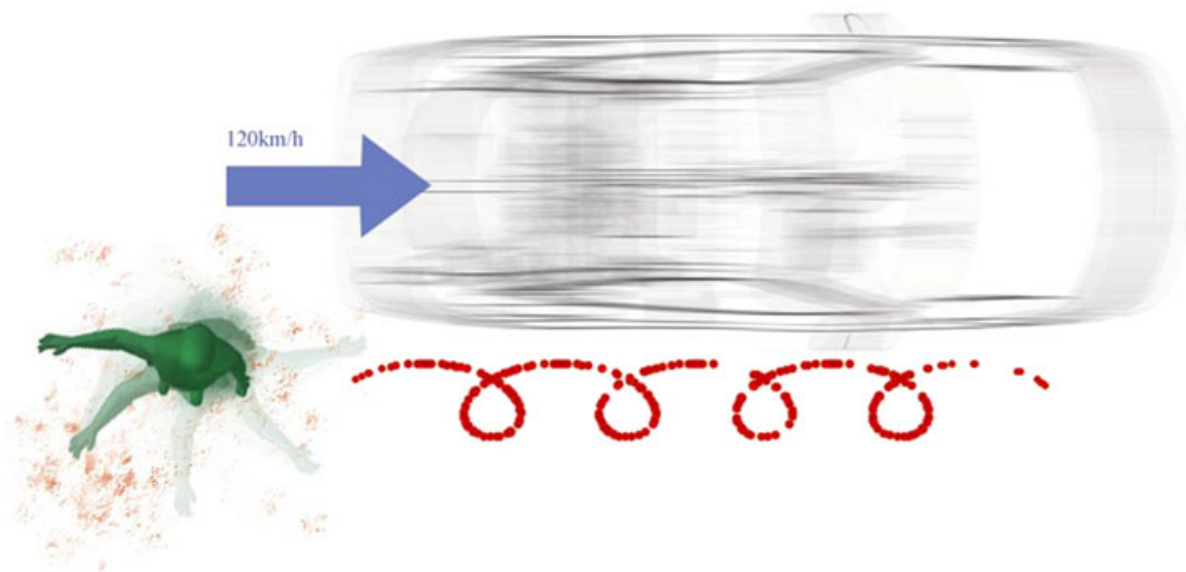

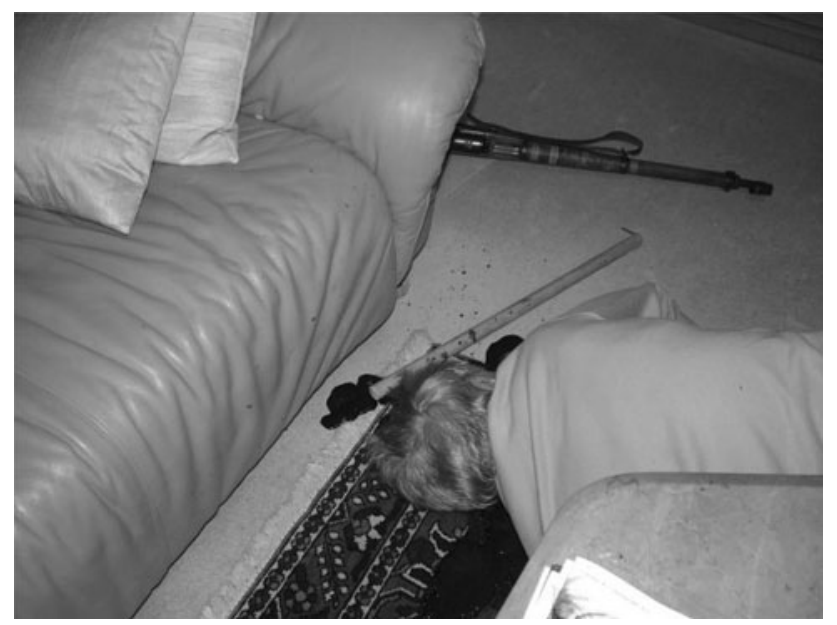

Fig. 5 Scene photograph of case 2. Note the rod with the L-shaped hook beside the head of the victim and the carbine beside the couch

The pictorial secondary interpretation clearly shows that the victim's arms were long enough to have pulled the trigger of the rifle with the rod. The resulting predicted course of one bullet through the head and the left shoulder explains the injuries seen on the body.
Gunpowder-residue testing proved positive on the left hand, further supporting our hypothesis that he shot himself holding the barrel with the left hand and pushing the trigger with the rod in the right hand.

Summary of case 2

Primary information:

- Injuries to the body as described in the text.

- Only one spent cartridge was present in the carbine and no other cartridges were found in the flat.

- 3D documentation of the external findings using CT.

- A CT model of the corpse was created and an exact scale model of the rod and rifle were built virtually with Autodesk $^{\circledR}$ Maya $^{\circledR}$.

- Virtual positioning the rifle to the entrance wound at the right side of the head made it obvious that the man could not have pulled the trigger in this position (arms too short).

Secondary interpretation:

- The presence of two wound systems, namely a contact gunshot to the right side of the head with bullet passage 
Fig. 6 Photographs of the head injuries of case 2. a Extensive, star-shaped lesion of the entrance wound. The ventilation tube was placed by the ambulance crew before death certification by a physician. b Round exit wound with an abrasion of the wound borders. This is due to the abrading of the outwardly extending skin against the shoulder during the exit of the projectile
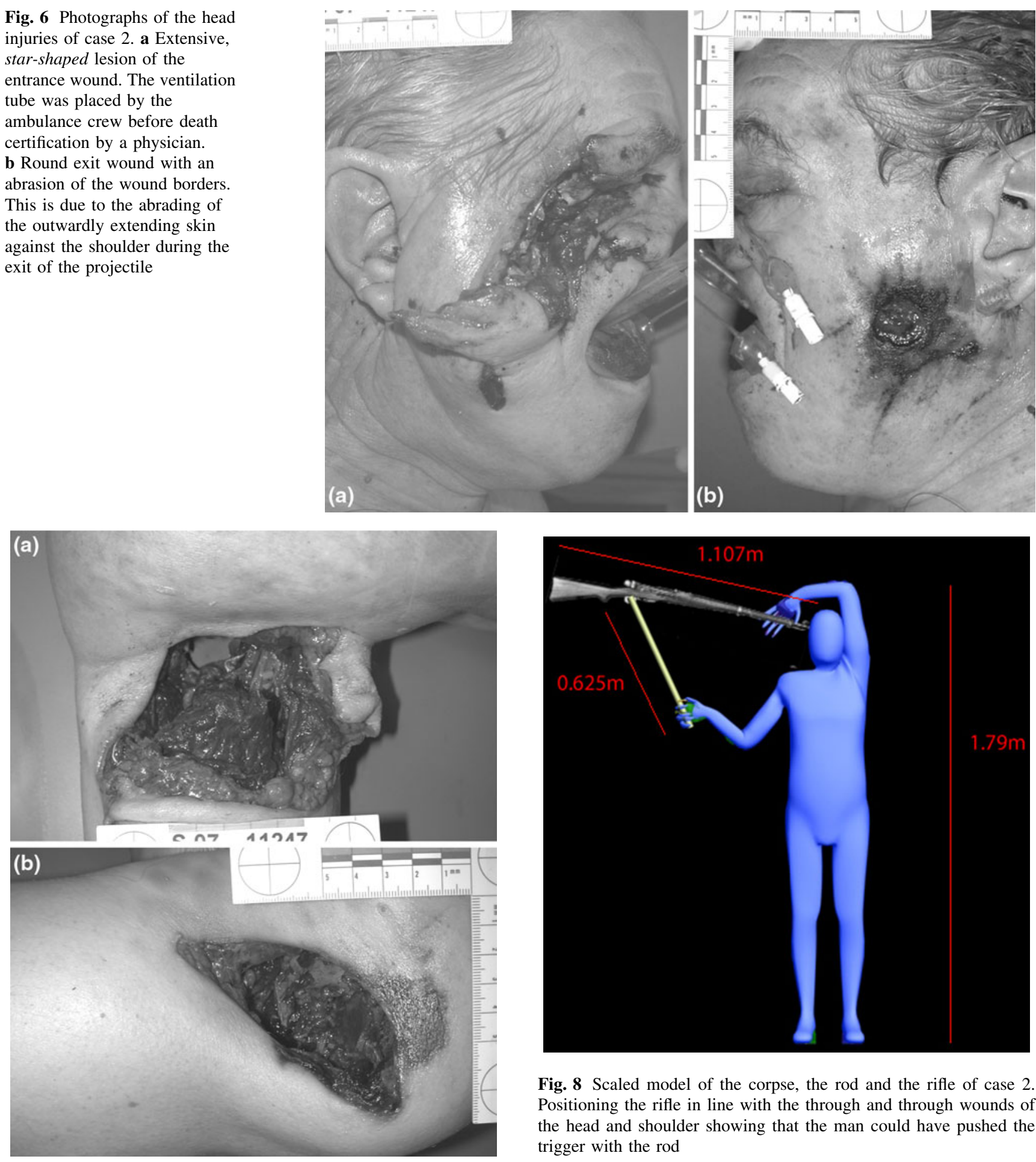

Fig. 7 Photographs of the left shoulder/upper arm region of case 2. a Anterolateral view showing re-entrance gunshot wound. b Medial view of the large destruction of the exit gunshot wound

to the left and through and though gunshot to the left shoulder (from ventral to dorsal) indicated the possibility of two gunshots.

- By pulling the trigger with the hook on the rod, the victim could very easily have shot himself.

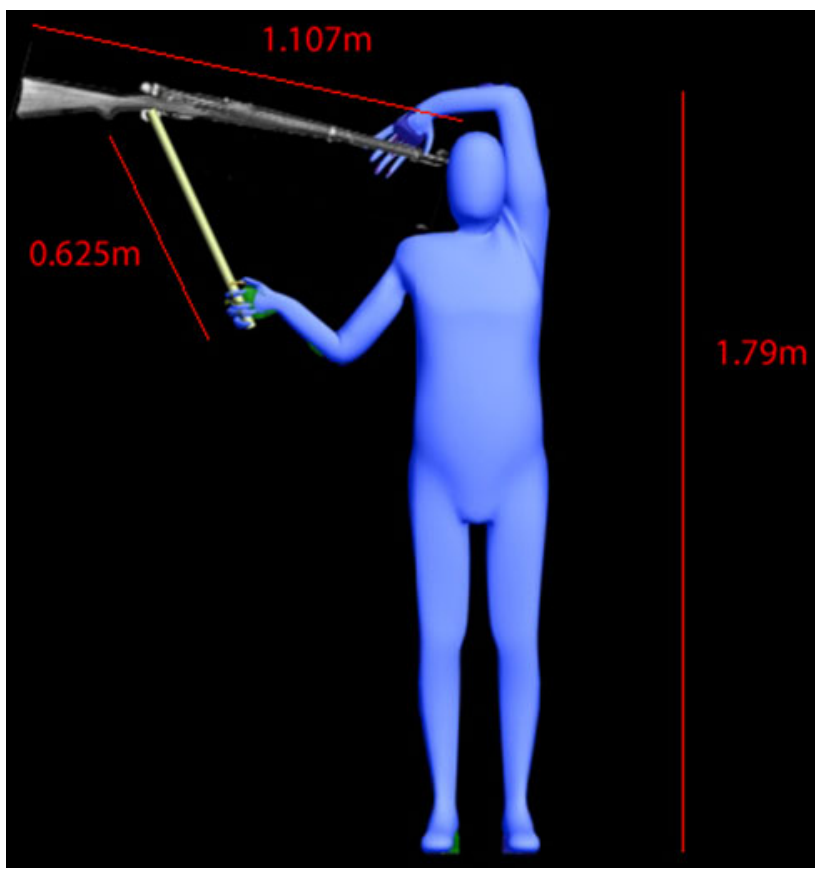

Fig. 8 Scaled model of the corpse, the rod and the rifle of case 2. Positioning the rifle in line with the through and through wounds of the head and shoulder showing that the man could have pushed the trigger with the rod

\section{Case 3}

A motorcyclist attempting to overtake an automobile at a narrow passage hit a second oncoming motorcyclist, who was later found dead at the bottom of a slope in close vicinity to the location of the accident. The surviving motorcyclist continued his ride without stopping. He later 
testified that the two motorcycles had barely touched, so there had been no reason for him to stop and investigate the damage.

Both vehicles were scanned with an optical scanner. Both surface and CT scanning was performed on the deceased motorcyclist (Fig. 9).

The forensic investigation needed to clarify whether the surviving motorcyclist's statement of ignorance to the result of the collision could be true.

Accident scene investigators found a damaged plastic covering and traces of dark material, consistent with the colour of the victims trousers, on the left side of the side trunk of the first motorcycle. Red traces, matching the red colour of the second motorcycle, were found on the left shoe and left trouser-leg of the victim. The victim's motorcycle displayed a badly damaged rear and extensive scratches on the right side.

At external inspection and autopsy, the following findings were seen:

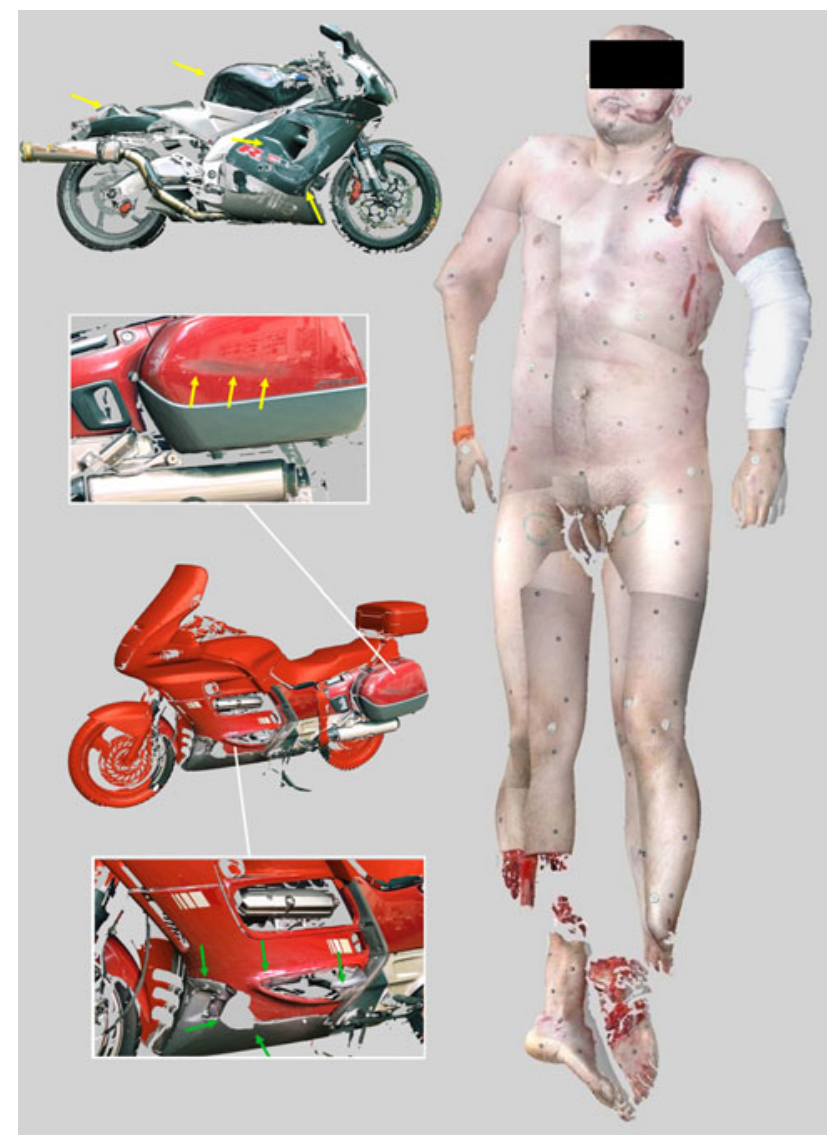

Fig. 9 Photographs of the green motorcycle of the deceased and the red motorcycle of the surviving driver as well as a 3D surface scan documentation of the victim. Note the damages to the vehicles (arrows). Of special interest is the paint trace (top insert) and the damage to the casing (bottom insert) of the surviving driver's motorcycle
Blunt cranial trauma A fracture of the left temporal bone with fracture lines radiating to the right skull base and extensive mid-face fractures, cortical contusions of the base of the left frontal lobe and of both temporal lobes, subarachnoid haemorrhage around both occipital and temporal lobes, hemorrhage into the left side ventricle, and a deep laceration of the left cheek were recorded.

Blunt thoracic trauma Contusion of the subcutaneous fatty tissue and musculature over the sternum, the left side of the chest and over the right shoulder blade, broad excoriation on the left ventral shoulder region, fracture of the left clavicle and the sternum, dorsal fracture of the ribs 1 and 2, tearing of the cartilaginous connection to the ribs 5 and 6 on the left and the rib 7 on the right to the sternum, fractures of the transverse processes of the thoracic vertebrae 1, 6 and 9, puncturing of the left lung lobe due to rib splinters, tearing of the pericardium, laceration of the left cardiac ventricle and of the papillary muscles, and $400 \mathrm{ml}$ blood in the right and $200 \mathrm{ml}$ blood in left thoracic cavity were found.

Blunt abdominal trauma Crushing of the ventral abdominal muscles on the right, contusion of the subcutaneous fatty tissue and the musculature of the left flank and of both buttocks, multiple lacerations of the liver and left kidney, disruption of the spleen, fracture of the transverse processes of the lumbar vertebrae 1,4 , and 5 as well as both articular processes of the 5th lumbar vertebra, and fracture of the left acetabulum were recorded.

Injuries to the extremities Fracture of the left elbow and of the left forearm and dislocation of the right elbow as well as blunt amputation of both lower legs was recorded.

\section{Results of case 3}

With the three models (two motorcycles and deceased rider) digitally captured, a reconstruction of the collision impact could be established. The height of the amputation of the left lower leg matched the damage seen on the second motorcycle. The red traces found on the left shoe and trouser leg of the deceased motorcyclist supported the assumption that a very intense contact between the red motorcycle and the victims left leg/foot led to the amputation (Fig. 10). The examiners therefore concluded that the surviving motorcyclist must have been aware of this severe collision.

Summary of case 3

Primary information:

- Injuries to the body as described in the text. 


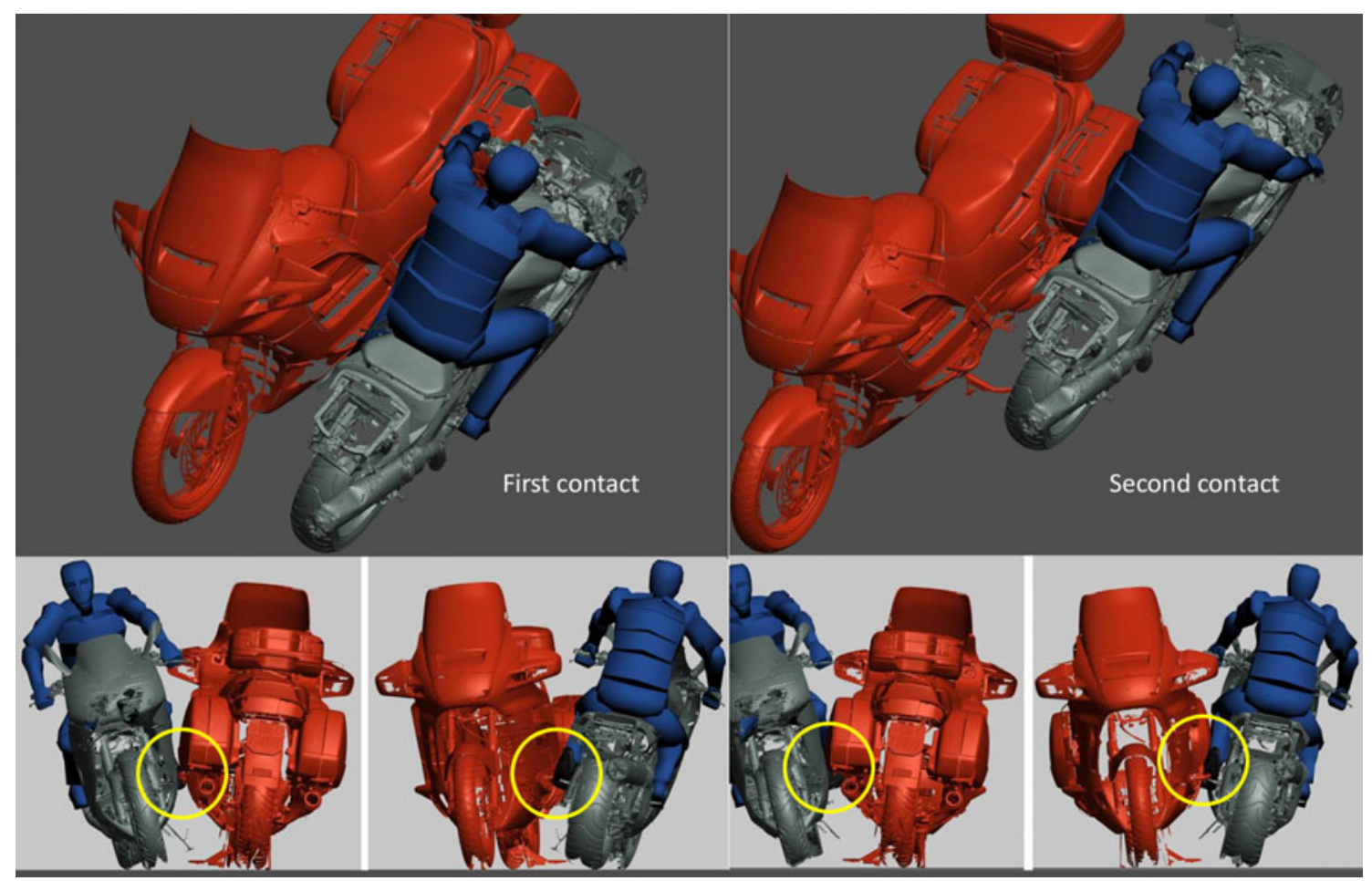

Fig. $103 \mathrm{D}$ reconstruction of case 3. In a first phase, the victims lower leg strikes the red motorcycle. In a second phase, the left trouser leg touches the side trunk

- 3D documentation of the external findings using optical surface scanning and internal body scanning (CT).

- A scale-model of the deceased rider was obtained from the surface scan.

- Virtual positioning of both motorbikes into their damage points, gave information on shape and position of the accident.

Secondary interpretation:

- To arrive at the assumed original riding position of the deceased motorcyclist, a 3D Max process was applied to the 3D data.

- By assembling all given primary information and the modelled position of both motorbikes and the deceased rider, the course of the collision could be reconstructed.

- This reconstruction and the examiners experience, led to the conclusion that the motorcyclist must have been aware of the severity of the accident.

\section{Discussion}

A picture says more than a thousand words. It conveys a message more clearly and leaves less room for alternative interpretation than a verbal report, where the listener has to visualise in their own mind the narrative event, and has to re-adjust constantly as the report progresses. Details might easily be omitted or wrongly imagined. Graphic presentations, in particular 3D models, certainly produce a better common basis between the viewer and the interpreter, as was shown in a recent case report by Gotsmy et al. [12], and therefore are conducive to further discussion. While they are always important to convey factual documentation, images become more important as the degree of complexity of the interpretation increases, as case 1 clearly shows.

The demonstration of the course of events, for example in a homicide, is often performed by play-acting. The defendant and/or witnesses can demonstrate to members of the judicature how they believe the event took place. Traditionally, these scenes are acted in accordance to the defendant's or witnesses' directions whilst relevant scenes are documented by photography and/or film. However, this play-acting requires a great deal of man-power (actors, defendant, policemen to guard the defendant etc.) and ideally the original crime scene. Access to the latter can pose great difficulties, especially if one is dealing with a crime committed on a busy street. In such a situation, image generation of relevant scenes based on the actual findings (room, furniture, size of the involved persons etc.) and the defendant's or witnesses' accounts, shown on the above stated incident, would be preferable. 
Another advantage of the translation of action into images is the compulsion for the interpreter to construct a complete picture, as case 2 shows. Omitted details are more conspicuous in images than in a verbal account. The interpreter is therefore forced to make a full interpretation and will be made aware of shortcomings requiring more investigation.

The clarity and ease of understanding associated with the pictorial reconstruction of a course of action, rather than a verbal description, has disadvantages, especially as members of the jury tend to believe whatever they see. Therefore, the pictorial presentation of secondary interpretation, reconstructing the course of events as presented by the expert to the best of his/her knowledge, may possibly be misunderstood as being fact rather than the expert's opinion regarding the course of events. Therefore, when giving a pictorial secondary interpretation one must emphasize repeatedly that this consists of an assessment based on the expert's experience and does not constitute hard facts.

One way of achieving this would be colour-coding derived figures as opposed to measured and well documented ones. For example, the examiner's degree of certainty could be mirrored by different shades or colours in order to distinguish primary (factual) information from secondary interpretation. This clear distinction could clearly assist in preventing fact from being confused with an expert's personal opinion or secondary interpretation.

\section{Conclusion}

The presentation of a complex sequence of events in written or oral form to members of the court and the jury may be difficult for a forensic examiner. We believe that the pictorial presentation of secondary interpretation, as shown here, can facilitate such an undertaking in certain cases, by showing the expert's personal opinion as to the course of events in an easily appreciable, graphic form. Furthermore, by depicting the interpretation, the examiner is forced to recapitulate each phase of their reconstruction, thus hopefully preventing rash conclusions.

In order to distinguish between facts and interpretation, the graphical reconstruction can show various degrees of certainty by using coloring or shading.

Scientific modelling and animation based on primary information and secondary interpretation, i.e. a 3D-reconstructed scene, has additional advantages. It has the possibility of making objects translucent when they obscure the view, and/or allowing the 3D-visualisation specialist to pick an optimal field of view by conveying the scene from different angles.

\section{Key points}

1. Secondary interpretation is based on primary information, namely facts and findings, and the examiner's experience.

2. A pictorial reconstruction of the secondary interpretation helps the reader in achieving a rapid overview of a perhaps complicated case.

3. In order to create a whole image, the examiner is compelled to look at all details, thus guaranteeing a thorough case examination.

4. As pictorial reconstructions tend to be taken as fact, the examiner must emphasise that the presented secondary interpretation is - as the name suggests merely his/her interpretation.

\section{References}

1. Thali MJ, Yen K, Schweitzer W, Vock P, Boesch C, Ozdoba C, Schroth G, Ith M, Sonnenschein M, Doernhoefer T, Scheurer E, Plattner T, Dirnhofer R. Virtopsy, a new imaging horizon in forensic pathology: virtual autopsy by postmortem multislice computed tomography (MSCT) and magnetic resonance imaging (MRI)-a feasibility study. J Forensic Sci. 2003;48:386-403.

2. Thali MJ, Jackowski C, Oesterhelweg L, Ross SG, Dirnhofer R. VIRTOPSY: the Swiss virtual autopsy approach. Leg Med (Tokyo). 2007;9:100-4.

3. Bolliger SA, Thali MJ, Ross S, Buck U, Naether S, Vock P. Virtual autopsy using imaging: bridging radiologic and forensic sciences. A review of the Virtopsy and similar projects. Eur Radiol. 2008;18:273-82.

4. Pomara C, Fineschi V, Scalzo G, Guglielmi G. Virtopsy versus digital autopsy: virtual autopsy. Radiol Med. 2009;114:1367-82.

5. Ljung P, Winskog C, Persson A, Lundström C, Ynnerman A. Full body virtual autopsies using a state-of-the-art volume-rendering pipeline. IEEE Trans Vis Comput Graph. 2006;12:869-76.

6. Poulsen K, Simonsen J. Computed tomography as routine in connection with medico-legal autopsies. Forensic Sci Int. 2007;171:190-7.

7. The Japan Society for Autopsy Imaging homepage. http:// plaza.umin.ac.jp/ ai-ai/english.htm.

8. Harcke HT, Levy AD, Abbott RM, Mallak CT, Getz JM, Champion HR, Pearse L. Autopsy radiography: digital radiographs (DR) versus multidetector computed tomography (MDCT) in high-velocity gunshot-wound victims. Am J Forensic Med Pathol. 2007;28:13-9.

9. Thali MJ, Braun M, Wirth J, Vock P, Dirnhofer R. 3D surface and body documentation in forensic medicine: 3-D/CAD Photogrammetry merged with 3D radiological scanning. J Forensic Sci. 2003;48:1356-65.

10. Thali MJ, Braun M, Buck U, Aghayev E, Jackowski C, Vock P, Sonnenschein M, Dirnhofer R. VIRTOPSY-scientific documentation, reconstruction and animation in forensic: individual and real 3D data based geo-metric approach including optical body/ object surface and radiological CT/MRI scanning. J Forensic Sci. 2005;50:428-42.

11. Buck U, Naether S, Braun M, Bolliger S, Friederich H, Jackowski C, Aghayev E, Christe A, Vock P, Dirnhofer R, Thali MJ. 
Application of 3D documentation and geometric reconstruction methods in traffic accident analysis: with high resolution surface scanning, radiological MSCT/MRI scanning and real data based animation. Forensic Sci Int. 2007;170:20-8.
12. Gotsmy WF, Ebert LC, Bolliger M, Hatch GM, Ketterer T, Thali MJ, Ruder TD. A picture is worth a thousand words: the utility of 3D visualization illustrated by a case of survived pancreatic transection. Leg Med. 2011;13:95-7. 